\title{
Building governance institutions across European Borders
}

\author{
Markus Perkmann
}

\begin{abstract}
:
This paper examines cross-border co-operation (CBC) and associated cross-border regions (CBRs) emerging within the European Union (EU). It analyses both as processes of institution building utilizing recent theories of governance and networks. The discussion is organized in four parts: ( 1 ) an overview of CBC in the EU to date and a suggested theoretical framework for understanding it; ( 2 ) a specification of $\mathrm{CBC}$ governance institutions as an articulation of horizontal and vertical networks; ( 3 ) an outline of the interests and agendas of the main actors involved in CBC, including the EU Commission as well as local, regional and central state authorities; and (4) an assessment of CBC governance as the outcome of the aggregate effects of the institutions and actors involved. The concluding section locates CB C within the emerging EU polity, arguing that it represents an example of the building of multilevel governance networks. CBRs, although loosely articulated, are characterized as terrains for producing new transnational actors and new opportunities for existing actors.
\end{abstract}

Key words: Cross-border co-operation, Cross-border region, Euroregion, Governanc, Policy network, European Union 


\section{INTRODUCTION}

Cross-border co-operation (CBC) is increasingly relevant in Europe. Today, there are hardly any border areas in which public authorities are not involved in some kind of co-operative initiative with their counterparts. The European Union has become increasingly involved in sponsoring $\mathrm{CBC}$ in areas contiguous to its internal and external borders, notably through its INTERREG programme. It is encouraging the development of cross-border regions (CBRs) as a means of facilitating the working of the Single Market and increasing the socio-spatial integration of the EU as a whole. These developments have stimulated an extensive and diverse research literature that is often confusing and somewhat contradictory.

This paper seeks to develop a more coherent understanding of CBC as a process of institution building, utilizing recent theories on governance and policy networks. The discussion is organized in four parts: ( 1 ) an empirical overview of CBC in the EU to date, and a suggested theoretical framework for understanding it; (2) a specification of CBC governance institutions as an articulation of horizontal and vertical networks; ( $\underline{3})$ an outline of the main actors involved in CBC, including the EU Commission as well as local, regional and central state authorities; and (4) an assessment of CBC governance as the outcome of the aggregate effects of the institutions and actors involved. The concluding section locates CB C within the emerging EU polity, arguing that it represents an example of the building of multi-level governance networks. Cross-border regions (CBRs), although loosely articulated, are characterized as terrains for the emergence of new transnational actors and new opportunities for existing actors. Methodologically, the paper takes into account a range of case studies and conceptual contributions, including my own work on the Viadrina Euroregion on the GermanPolish border. (ㅁ1)

The form of $\mathrm{CBC}$ considered here is distinctive in that it involves the more or less institutionalized collaboration between sub-national authorities in contiguous areas close to EU state borders. Furthermore, for the purpose of this analysis, CBC is confined to those arrangements that involve the European Commission and, consequently, national governments. This restriction is justified as virtually all CBC initiatives in fact receive support from the European Commission under its INTERREG Community Initiative and CBRs can be defined in terms of the combined territorial remits of the local and regional authorities participating in CBC initiatives. Thus, the analysis excludes both the larger 'Working Communities' as well as interregional co-operation among noncontiguous authorities (see Table 1).

Insert Table 1 about here

\section{EMPIRICAL OVERVIEW AND THEORETICAL FRAMEWORK}

General characteristics of European CBC

The origins of CBC in Europe may be traced to certain areas of Europe, such as the BENELUX countries, the western borders of Germany, or the Swiss-French-German border areas, where various collaborative initiatives date back to the 1950s and 1960s. It was on the Dutch-German border that the expressions 'Euregio' and 'Euroregion' were coined. In its original meaning, Euroregion denoted a formal collaboration between border municipalities involving a council, a presidency, a secretariat and subject-oriented working groups. Apart from local territorial authorities, members are sometimes also recruited from other public agencies, associations and chambers of commerce and, more recently, the notion has been used to cover a larger range of CBC arrangements.( $\underline{\text { n2}})$ 
For local and regional authorities, co-operating across borders means they enter a field long reserved for central state actors. In the 1960s and 1970s, various bi-lateral and multi-lateral governmental commissions were established to deal with issues such as local cross-border spatial planning and transport policy, but they did not grant access to local authorities (AYKAC, 1994). However, over the last 20 years the scope for noncentral governments (NCGs) to co-operate across borders has been widened considerably on the initiative of two supranational bodies, the Council of Europe and the European Union. Whereas the Council of Europe has been particularly active in improving the legal situation, the Commission of the European Union provides substantial financial support for CBC initiatives.

Legally, the idea of an administrative body in charge of a subnational cross-border area is relatively difficult to put into practice. The first CBC initiatives were based on agreements with varying degrees of formality and mostly relied on good will. The classical form of a Euroregion is the 'twin association': on each side of the border, municipalities and districts form an association according to a legal form suitable within their own national legal systems, (n3) and the associations then join each other on the basis of a cross-border agreement to establish the Euroregion.

In 1980, on the initiative of the Council of Europe, the so-called Madrid Convention ( $\underline{\mathrm{n} 4}$ ) was introduced as a first step towards CBC structures based on public law. The Convention -recently updated with an Additional Protocol -- provides a legal framework for the completion of binational and multinational agreements to allow for public law CBC among NCGs (DOLEZ, 1996). Examples of such agreements are the German-Dutch cross-border treaty of 1991 and the BENELUX Cross-border Convention of 1986 (ASSOCIATION OF EUROPEAN BORDER REGIONS (AEBR), 1997, A3-3), and the Euroregion Rijn-Waal on the Dutch-German border has operated as such a cross-national public body since 1993. However, the regulations delivered by such agencies are binding only on the public authorities within the cross-border area concerned and not on civil subjects (DENTERS et al., 1998).

Compared with the Council of Europe, the CBC-related activities of the European Union are primarily of a financial nature. Many $\mathrm{CBC}$ initiatives are eligible for support under the INTERREG Community Initiative launched by the European Commission in 1990 and reconfirmed in 1994 as INTERREG II. The INTERREG programme is part of the Structural Funds policies but, as a Community Initiative, is more autonomously managed by the Commission than the standard regional policies.

All NUTS III areas located on external (ㅁ5) and internal land borders, as well as some maritime areas, are eligible for INTERREG II which has an overall budget of 2,400 million ECU for CBC over the 1994-99 period, corresponding to approximately $1.5 \%$ of the overall Community budget for regional policies. As INTERREG is by far the most important source of funding for most CB C initiatives, they must obviously comply with the modalities set out in EU regulations. Operational Programmes (OPs) are formulated between participating Member States for their respective border areas and submitted to the European Commission for approval. This means that European funds are granted to Member States and not directly to Euroregions or similar cross-border bodies themselves. Normally, public authorities and semi-public organizations, such as chambers of commerce, employer organizations, unions or research institutes, are then eligible for project funding.

As the Member States often delegate the design and implementation of the O P to regional authorities, usually a multiplicity of public agencies is involved in CBC. For instance, in France CBC affects the responsibilities of 'concentrated (n6) (DATAR) and deconcentrated central state agencies (prefectures), the regions, the departements and single local authorities. In Germany, central state departments, the Lander, the districts (Kreise), municipal associations, inter-municipal bodies and local authorities are involved. The expenditures for 
co-funding allowed by the European regulations are normally shared by these different levels of government.

The limitation to NUTS III areas implies that in most cases the regions are too large to be considered 'border areas'. For instance, within the German Lander, CBC normally concerns the level of districts (Landkreise) or/and municipalities organized in municipal associations (Kommunalvereinigungen). In fact, in its classical form, rather than being a regional domain, CBC was first invented by local authorities, i.e. municipalities. Today, the most dynamic $\mathrm{CBC}$ initiatives are still driven by municipal and inter-municipal action. However, with the introduction of INTERREG, CBC initiatives became increasingly embedded in networks involving higher-level public authorities. Thus, it is clear that CBC is not solely at the discretion of locally based actors willing to co-operate. Rather, $\mathrm{CBC}$ consists of three relatively separate institutional realms: ( 1 ) the locally based structures (e.g. the Euroregions); ( 2 ) the INTERREG related structures; and ( $\underline{3}$ ) the governmental commissions (some cases).

As the governmental commissions generally do not interfere with daily affairs, CBC is de facto governed by a twin structure: the CBR organizations with their representative and administrative bodies, and the supralocal structures constituted by the INTERREG committees and the authorities involved. Both 'twins' are usually bi-national. Whereas the design and submission of project proposals is delegated to the CBRs, the final project selection remains with the INTERREG coordination bodies. The latter consist of a supervisory monitoring committee and a steering committee, responsible for all operational matters and final decision making on projects. There are cases in which the steering and the monitoring committees have been merged to simplify decision making. Both committees are normally composed of civil servants of the public authorities responsible for the implementation of INTERREG, i.e. national or regional authorities, as well as European Commission officials in the case of the monitoring committee. Often Euroregions are granted a limited number of seats on a voluntary basis.

Given this particular distribution of responsibilities, a relatively clear division of labour between the two tiers of $\mathrm{CBC}$ governance prevails. Basically, decision making on the expenditure of INTERREG funds remains with the steering committees, i.e. the authorities responsible for the implementation of Structural Funds' policies. This means that the local CBC structures, e.g. the Euroregions, do not formally administer the INTERREG budget but are in fact themselves 'projects' that receive INTERREG funding for 'technical assistance'. Special conditions apply to European Union support for CBC on the external EU borders. As part of the Structural Funds policies, INTERREG support is restricted to EU areas only (territoriality principle). To facilitate CBC across external EU borders, a special budget within PHARE (PHARE CBC) was created to help border areas in non-member countries in Eastern Europe to match the INTERREG funding for adjoining areas in the EU.

Insert fig. 1 here

Interpreting CBC

In the growing body of literature on the topic, there is a tendency to overemphasize CBRs as emerging territorial units equipped with self-governing capacities. The hypothesis proposed here is that $\mathrm{CBC}$ is an emergent effect rather than a single deliberative strategy and for a theoretical perspective on CBC, the following four points are of particular relevance.

Firstly, CBC has to be seen as an aggregate outcome of various relatively decentralized processes of institution building with strong involvement by non-local actors. Cross-border initiatives cannot be assumed to have single and coherent objectives. Rather, a multiplicity of 
actors operates in an institutional context of opportunities and constraints that is not predominantly of their own making. As a consequence of their actions, the institutional setting itself undergoes continuous changes resulting in irreversible and historically specific trajectories. Such ideas about the building and evolution of institutions can be extrapolated from a more sociologically inflected 'new institutionalism' recently emerging as a supradisciplinary paradigm in a range of fields. (n7) To be more precise, I build on literature which sees neither transaction costs nor methodological individualism as key explanatory principles. This new institutionalism pays particular attention to the role of routines, procedures and norms in shaping the substantial direction of organizational strategies and policies (POWELL and DI MAGGIO, 1990). Social actors are conceived as embedded in specific social and discursive contexts that shape their orientations, agendas and actions (GRANOVETTER and SWEDBERG, 1992). They are situated in environments that are controllable and transparent only to a limited degree, and their strategies often follow a 'garbage-can' logic determined by conjunctural circumstances and windows of opportunities (MARCH and OLSEN, 1989). From such a viewpoint, institutional change is not linked to any optimization logic but is seen as induced by a mixed logic of strategic action (path-shaping) and evolution (pathdependence) (HAUSNER et al., 1995).

Secondly, the establishment or modification of institutions usually affects the opportunity structures and constraints which the actors face in the attempt to pursue certain agendas. Institutions are never neutral contexts -- they privilege certain actors, certain time and space horizons, and certain strategic agendas over others. In other words, the transformation of institutions affects their 'strategic selectivity' (JESSOP, 1996). The notion of 'strategic selectivity' refers to the bias of institutions towards the formation and realization of specific strategies by specific collective actors. This does not only mean that institutions offer certain actors privileged power positions to formulate and to pursue their strategies. As institutions by definition resist attempts to be employed for certain goals on a purely voluntaristic basis, in addition they produce structural effects on social processes. For instance, the consideration of such structural effects informs the debates about the benefits and drawbacks of networks that have recently been emphasized by a number of authors (e.g. MARIN, 1990; MESSNER, 1997)

More generally, effects of institutions on social processes are at the heart of the question of governance, including issues of guidance, steering or regulation (JESSOP, 1997; LE GALES, 1998). The central concern here is to show how a multiplicity of actions can result in more or less coherent aggregate effects on certain processes in time. The degree to which this is intentionally organized has been grasped with the notion of the 'mode of governance' understood as a specific balance or articulation between top-down guidance and coordinated self-organization (JESSOP, 1997). Especially if one considers more decentralized modes of governance, such as networks, it becomes clear that it cannot be assumed that governance institutions are necessarily functional for specific purposes. In contrast, the 'object of governance' is not preconstituted but co-evolves with the operation of governance institutions (PERKMANN, 1998). An immediate consequence is that, for instance, CBC institutions are not necessarily directed at the management of sub-national areas stretching across borders (CBRs) as their objects of governance. In other words, although CBC institutions exist as policy networks, the nature of the policy problem is by no means well defined from the outset.

A last point concerns the always circular relationship between actors and institutions. On the one hand, actors face a horizon of possible actions established by the institutions they are embedded in. On the other hand, however, institutions crucially affect the constitution of actors, in the sense that any institutional change may transform the interests and identities of existing actors and even give rise to the formation of new actors. Applied to the prospects of CBC, this points to the possibility that genuine cross-border actors may co-emerge with the building of cross-border governance institutions. It will be shown that -- as a more or less 
unintended effect -- CBC governance is in fact helping to create new opportunities for actors that might change the strategic landscape both in border areas as well as on a European level.

\section{EXPLORING CBC GOVERNANCE: INSTITUTIONS AS NETWORKS}

Which institutions do actually emerge in the course of CBC? Generally speaking, as there are no preconstituted public authorities stretching across borders, CBC cannot be pursed along the conventional lines of public action. Given this situation of trans-territoriality, some type of network integration among actors on both sides of the border can be expected. In fact, the networked structure of CBC governance has been confirmed by a number of empirical studies as, for instance, BECK's, 1997, most detailed analysis of the PAMINA in the Upper Rhine area between Germany and France. Similarly, CHURCH and REID, 1996, emphasize the variable geometry of networks in the case of cross-Channel co-operation.

Obviously, for a useful adoption of the network metaphor, the precise structure of these networks must be investigated in more detail. Two dominant empirical characteristics of CBC networks will be pointed out. First, they are policy networks with generally little involvement of the private sector. Second, attention to the horizontal dimension of CBC --co-operative relationships among NCGs -- should not lead one to overlook its vertical dimension. As can be imagined, the INTERREG-related governance structures in particular show a pronounced vertical structure. They operate as multi-level networks involving virtually all levels of public administration from the local, district, regional, central state to the European level, but they also maintain horizontal links to their counterparts on the other side of the border, formalized in the monitoring and steering committees. Given their administrative character, they mainly comprise civil servants and operate along procedures defined within their respective authorities and the regulations of the European Union. Using a category proposed by RHODES, 1990, these networks are best characterized as 'technocratic' as they are run by specialist public sector administrators. More precisely, as their raison d'etre is the implementation of INTERREG OPs, their common goal is to develop or to stimulate adequate project proposals eligible for support while securing a balanced distribution of co-funding.

Within the different authorities, $\mathrm{CBC}$ matters are not necessarily dealt with in specialized administrative units (BECK, 1997, p. 174). For higher level bureaucracies, INTERREG forms part of the wider policy field of the European Structural Funds' policies. The same is true for the European Commission whose representatives in the monitoring committees are usually responsible for a whole range of Community Initiatives in specific areas. Thus, the routines and administrative procedures for $\mathrm{CBC}$ measures tend to be the same as, say, for the implementation of standard ERDF policies. CBC is a 'horizontal' subject matter usually involving a large number of departments as well as the Structural Funds' managers. This situation adds to the network character of $\mathrm{CBC}$, and it also adds to the co-ordination difficulties and time delays associated with the implementation of the $\mathrm{O}$ Ps.

By contrast, the local CBC structures tend to be organized as horizontal networks not transgressing the local level, involving inter-municipal relationships both on each side of the border separately as well as on a cross-border basis. They usually comprise elected politicians and local public sector managers, as well as academics from local universities or other experts, and they tend to be based upon good will, normative commitment and voluntary activity. Within the terminology of RHODES, 1990, these local networks are 'topocratic' in the sense that the individuals involved are 'generalists', often representing certain constituencies. Furthermore, Euroregions tend not to be homogeneously integrated networks but consist of two or more sub-networks on each side of the border. Often this is illustrated by the persistence of two separate secretariats that have been merged only in the more advanced cases, such as the EUREGIO on the Dutch-German border (SCHACK, 1997). The INTERREG modalities re-enforce this situation because co-funding has to be provided by the respective Member State authorities separately. 
In principle, the local networks can exist independently from the INTERREG networks. This is proved by the number of CBC initiatives developed prior to the launch of INTERREG. However, given the considerable financial incentives, in virtually all cases the local networks are integrated with the INTERREG network although their precise articulation varies greatly. On the one hand, there are cases where local networks, as defined earlier, do hardly exist. In these cases, CBC is exclusively confined to the implementation of the INTERREG OP and does not involve any further independent grass-roots initiatives. Such a situation prevails on the Italian--Austrian border where no inter-municipal Euroregions have been established but CB C is managed by regional authorities, i.e. the Italian provinces and the Austrian Lander (LUVERA, 1996). By contrast, on the German borders, the municipalities tend to be the driving forces behind CBC. As inter-municipal associations with relatively formalized structures and their own organizational resources, they operate rather independently from the authorities responsible for the implementation of INTERREG, i.e. the Lander in Germany or the central state authorities in more centralized countries. (n8) However, usually the local structures and the INTERREG-related structures interact on a more or less regular basis. The division of labour differs from case to case. Formally, the Euroregions have no right to be represented in the INTERREG steering committees. How closely they are involved in decision making, depends on their relationships with the Land or central state authorities. For instance, in Brandenburg, (n9) the two concerned Euroregions are granted one seat each whereas the remaining seats in the committee are taken by several ministries of the Land administration. Formally, the Euroregions' impact upon decision making on project funding is therefore rather limited. In other cases, the Euroregions are not even involved in implementing the operational programmes although they are among the bodies eligible for receiving INTERREG funding (LIBERDA, 1996). By contrast, on the Dutch-German border, Euroregions are more closely involved in the INTERREG programme measures and the cooperation between them and the Land administrations of North Rhine-Westphalia and Lower Saxony appears to work well. Here, the Euroregions have a certain degree of autonomy in the design and implementation of the INTERREG OPs and European grants and national matchfunding are paid into a single account administered by North Rhine-Westphalia (SCHACK, 1997).

It can be concluded that the introduction of INTERREG had a considerable impact on the development trajectory of most CBC initiatives. Where they had existed beforehand, local CBC networks were complemented by more vertically integrated policy networks. This tendency towards vertical integration also appears to have been enforced in the course of the life cycle of European CB C support that developed from initial pilot projects in the late 1980s to INTERREG I in 1990 and INTERREG II in 1994. CHURCH and REID, this issue, note that whereas at the beginning co-operation was driven by local and regional policy responses to the Channel Tunnel, later with the adoption of INTERREG II the central state has become more closely involved. A similar pattern has been found by BECK, 1997, in case of the PAMINA. However, in both cases, the move towards vertical integration has had a catalyst function that helped CBC networks to move from more or less ceremonial interaction towards the realization of concrete projects.

As an evolving process, the building of CBC institutions is sensitive both towards the initial state and the structural conditions prevailing over time. From such an evolutionary viewpoint, the empirical variety of CBC arrangements can be linked to the following key factors. First, it makes a considerable difference whether INTERREG support was accommodated into existing local CBC structures, or whether the launch of INTERREG (or its pilot predecessors) actually triggered $\mathrm{CBC}$ initiatives that had not been existing beforehand. In the latter cases, CBC tends to be driven by central or regional authorities for which the bidding for Structural Funds support belongs to their administrative repertoire of routine activities. Thus, the technocratic element, as defined earlier, is more accentuated in these cases. As subject-matter oriented intranational and transnational 'grant coalitions'(COCHRANE et al., 1996), they are less oriented towards restricted cross-border spaces than locally driven $\mathrm{CB} C$ initiatives 
established before INTERREG support was available. But also, where CBC had existed beforehand, European support has exerted a considerable impact both on the material priorities pursued as well as on the strategic behaviour of the NCGs involved.

Second, diverging patterns of territorial organization in different countries affect the relative position of authorities in the CBC game. For instance, in Germany, the Lander are so large that only narrow strips on their borders are eligible for INTERREG support. This gives border municipalities and inter-municipal associations the opportunity to initiate and shape CB C as involving local actors is among the INTERREG requirements. By contrast, in countries where the regional constituencies are small enough to entirely cover the eligible NUTS III area, they tend to conceive themselves as natural leaders in pursuing CBC.

Third, the degree of devolution of the design and implementation of Structural Funds' policies to the regional scale in different EU Member States has a crucial impact upon the precise characteristics of developing CB C institutions. Thus, while in Britain or in Poland central governments will be strongly involved in CBC, in Germany the Lander or their deconcentrated administrative units will play a leading role.

\section{ACTORS AND AGENDAS: WHO GOVERNS?}

Networks are loose-tie inter-organizational relationships and, as such, they offer the participating actors a relatively structured environment for pursuing their agendas. In the following, the interests and agendas of three main groups of actors in CBC are briefly outlined: the grass-roots border actors; the authorities responsible for INTERREG; and the European Commission.

First, for local authorities and related public agencies operating in border areas an obvious and immediate benefit of INTERREG-supported CBC is the access to additional funding as they are eligible project leaders. Usually, certain pivotal cities or regions in border areas tend to take the initiative, often by dedicating part of their own organizational and human resources to CBC. For these authorities, participation in CB C can be seen as part of their more general strategies as 'entrepreneurial regions/cities' aimed, for instance, at the attraction of inward investment that may be achieved through a collaborative place marketing of a cross-border area. Furthermore, pre-existing inter-municipal agencies and associations, such as spatial planning agencies operating in the border areas, show a strong interest in CBC. This concerns, for example, the regionale Planungsgemeinschaften -- inter-municipal bodies responsible for district spatial planning in some German Lander. As they often cover areas that match the NUTS III areas eligible for European CBC support, they perceive themselves as representing the appropriate spatial level for dealing with the issue given that $\mathrm{CBC}$ is, after all, traditionally associated with spatial planning.

The second important group is the authorities responsible for designing and implementing INTERREG OPs, usually central state agencies or regional authorities such as the Lander in more decentralized countries. These authorities have to apply for INTERREG funds and ensure that the approved funds are spent within the time limits specified. Furthermore, they have to abide by the relevant European regulations, i.e. policies have to programmed in advance, they have to be project-based involving local actors, and they have to satisfy the material priorities of the Structural Funds. The pressure to take advantage of European funds is particularly accentuated in Objective 1 areas where the European grants cover up to $75 \%$ of the total costs. An INTERREG OP has to be submitted at all costs -- regardless of whether or not there are any local CBC initiatives. Where no grassroots initiatives exist, the authorities have to act as network animators and to mobilize potential project leaders. Not least, for central or regional authorities, border areas are a part of their territory. Thus, especially in cases where no separate administrative unit is established for dealing with CBC, it is likely that the agencies involved will perceive $\mathrm{CBC}$ policies from the perspective of their more 
general objectives. For instance, CHURCH and REID, 1996, note that the UK Government pledged INTERREG funding for areas already eligible for Structural Funds support. In Brandenburg, considerable INTERREG resources are being dedicated to flood protection although the Euroregions argued that this would not satisfy the criterion of a CBC project.

Third, as policy principal, the European Commission plays an important role in CBC. After the reforms of the Structural Funds, the general EU approach to regional policy has increasingly been oriented towards a variety of networking policies. This includes initiatives such as inter-urban and interregional networks, SME-networking and regional technology development plans, especially as experimental pilot projects. INTERREG itself had been tested in a series of these so-called 'Article 10 initiatives'. CBC is an experimental field and a particularly challenging case for such advanced regional policies based on 'soft' interventions. Within DG XVI, CBC was indeed treated as absolute priority at the beginning of the current programming period.

As can be inferred from these short actor profiles, there is no easy answer to the question 'who governs?' In a way, everybody (co)-governs. As with all networks, there is no core agent that could be identified with any of the network members. CBC networks are characterized by a series of interdependencies particularly in the vertical dimension on each side of the border separately and there are no unequivocal principal-agent relationships. Thus, instead of a final verdict, some more general observations shall be made. CBC offers individual and collective actors a relatively new and fertile arena for launching new policy initiatives, often upon the personal initiative of interested individuals. For instance, it offers opportunities for administrators and local politicians to pursue objectives such as improving cross-border infrastructure. In general, conflicts are minimized by common interests in drawing down INTERREG funds although, at times, the local actors may interpret priorities differently from the higher-level authorities. Any such conflicts are usually intra-national, i.e. along the vertical network lines. Cross-national conflicts are less likely as funding comes separately for each national area and there is little incentive for the involved authorities not to agree on their partner's project proposals as long as they agree on theirs. However, consensus is more problematical, of course, where co-operation impinges on ethnic minority issues or contested national boundaries (LUVERA, 1996). Finally, one has to bear in mind that CBC funds are of relatively modest significance to most of the actors involved and, as 'windfall' revenue, they tend to be employed in the context of more general policy objectives. (․10)

\section{ASSESSING CBC GOVERNANCE: EFFECTS AND OUTCOMES}

If governance is about causal relationships between 'governing' institutions and their effects on specific processes, what does CBC actually do? Three effects of CBC governance may be identified: the delivery of European policies; the creation of unstable and spatially nested inter-territorial coalitions; and the provision of a strategic space for the emergence of new actors in border areas.

\section{Policy delivery}

Partly at the request of the European Union, and partly because of the mobilizing force of local interests, local networks play an essential role in delivering INTERREG policies. The Commission envisages the devolution of the implementation of CBC projects to the local or district level. As a 'hollow' organization, it needs to find new partners for policy delivery, as it is prevented from direct policy implementation by organizational and legal limitations. On a trans-European level, it is supported by the transnational Association of European Border Regions (AEBR) which operates a 'think tank', gives advice to its members and acts as a European interest organization for CBRs. (ㅁ11) 
As the Member States are accountable for implementing European policies, however, local $\mathrm{CBC}$ networks also fulfil an important policy delivery function for them. In particular, the secretariats and working groups of the Euroregions serve as a relay station between the local context and the higher level authorities involved. Apart from collecting project proposals, they are usually also engaged in developing possible project ideas and addressing potential project leaders. In a way, they function as project stimulators and local network managers. They also help to formulate the development concepts that are a precondition for OP proposals to the Commission for central state authorities. As a consequence, CBC initiatives are considerably shaped by the procedures and routines applying to the implementation of Structural Funds in general.

Spatially nested and unstable trans-territorial coalitions

$\mathrm{CBC}$ can result in rather volatile and short term coalitions among NC Gs in different countries. Several co-operation initiatives may compete against each other in the same area. For instance, on the French-Spanish border, the Catalunia communidad autonoma and the city of Barcelona are rivals in the attempt to create functioning co-operation structures in the area. This concerns cross-border co-operation (Catalunia in the Euroregion; Barcelona in the C-6 network, a collaborative arrangement between cities close to the French-Spanish border) as well as interregional co-operation (Catalunia in the Four Motors, Barcelona in the Eurocities). MORATA, 1996, p. 124, notes the 'striking' absence of co-ordination between the Euroregion and the C-6, although they often pursue identical or complementary strategies. Similarly, in the maritime border areas between England and France, the relationship between CBC initiatives is characterized by competition and lack of co-ordination (CHURCH and REID, this issue).

If one considers that CBC does not just consist in horizontal co-operation but is shaped by vertical policy implementation, these patterns can be more easily explained. What really matters are not CBRs as such, but successful multi-level policy implementation. As different co-operation initiatives in the same area might be backed by different vertical policy networks, it is no surprise that they do not necessarily seek co-ordination between themselves. This can be also taken as empirical evidence of the fact that the topocratic networks across borders tend to be less stable than the vertical technocratic networks evolved in the course of European policy implementation. However, this seems to apply particularly to those cases where CBC structures did not exist before INTERREG was launched.

'Lean' governance and new opportunities

Cross-border development concepts usually have a 'catch-all' quality and originate from the attempt to apply for INTERREG funding. But even if they were more operational and concrete in their policy programming, the loosely coupled local cross-border networks would hardly be in the position to develop the necessary degree of strategic coherence to implement them. Usually, their organizational capacities are too 'lean' to have a considerable impact on strategy coherence. This has to do with a number of factors linked to the complex policy patterns described above. First, projects have to overcome the hurdle of the steering committees. Given the heterogeneity in terms of their projects and institutional affiliation, participating actors are likely to engage in bargaining games rather than in goal-oriented problem solving (SCHARPF, 1991). Second, participants will usually want to ensure that the provision of co-funding benefits their own constituencies which means they will avoid positive externalities spilling across the border without a corresponding effect from the other side. This is not problematical, as long as all projects are realized as planned in the initial proposals and as long as the envisaged EU support matches the expectations. However, if there are any variations or performance problems, experience shows that it is difficult to change or introduce new projects because this affects the equal balance of burdens sought at the outset (BECK, 1997). Also, project proposals reflect both budget constraints and 
opportunities within the authorities involved. Thus, instead of being oriented to a coherent strategy, they might be adjusted to available co-funding. Third, the Euroregions cannot guarantee the successful implementation of a range of project proposals even if they had been laid out in coherent development concepts because they do not actually carry them out themselves. Once approved, it is project leaders who are responsible for realizing projects and become accountable to the steering committees and any providers of co-funding. Here again it is very important how closely Euroregions and steering committees work together.

CBC institution building is not merely constraining, however. It also provides changing opportunity structures for various actors. CBC provides an opportunity for certain organizations, such as Euroregions, to grow. As a type of cross-border regional development agency, the Euroregion secretariats and 'info centres' are responsible for a newly defined cross-border space and are at least organizationally distinct from each of the participating authorities. Whereas the Euroregion councils are inter-governmental in their character, the secretariats are organizational bodies whose constitutive purpose is linked with cross-border spaces, i.e. CBRs. For instance, in the case of the Viadrina Euroregion, CBC is pursued with the objective to create an 'integrated economic region'. The secretariats are an important driving force behind strategies such as encouraging inward investment. If managed by wellqualified professionals, they may be able to emancipate themselves from the particularist interests represented in the steering committees or councils. Their potential influence lies in their considerable expertise and networking resources more than in their financial resources. Even when the latter are limited, some of them have been creative in assuring their own existence by attracting further resources and offering services sometimes in areas other than CBC, such as the creation of employment or the dissemination of information on European policy programmes. In addition, Euroregions seem to play the role of 'incubators' for third organizations, particularly public agencies, such as 'info-centres', investor centres or territorial marketing agencies.

\section{CONCLUSIONS}

I have attempted to show that $\mathrm{CBC}$ is a process of institution building involving a complex network of networks that simultaneously constrains and empowers participating actors. Two main types of sub-networks were identified: 'horizontal' networks among the local actors; and 'vertical' networks linking local actors with higher level state and European administrations. The label of 'cross-border co-operation' provides a broad scope for the participating actors to integrate CBC activities into their more general agendas following a 'garbage-can' logic (MARCH and OLSEN, 1989). Taking together the loosely coupled interaction patterns, the considerable number of participating actors and the broadly defined policy objectives, the outcome of CBC governance has to be seen as a compounded effect rather than as the realization of deliberative strategies.

Three main conclusions can be drawn from this investigation into the anatomy of CBC. Firstly, CBC as a policy field involves multi-level governance. In this regard, CB C is symptomatic of the newly emerging European polity characterized by the operation of crosslevel networks encouraged by Structural Funds (HEINELT and SMITH, 1996). CBC has to be regarded as state action although, at the same time, it points to the changing nature of statehood resulting from European integration and the relative changes in the modalities of public action. In any case, however, there is relatively little evidence that CBRs challenge the 'dominance of the state' (MURPHY, 1993) or are a 'perforation' of state sovereignty (DUCHACEK et al., 1988).

Secondly, the low degree of strategic coherence in the building of CBRs can be reasonably explained by the network structure of CBC. On the one hand, CBC is open to a variety of actors and compatible with a range of their objectives. The local actors operate under the supervision of their respective national authorities which are accountable to the European 
Union. This facilitates a rather loosely coupled network structure ('lean' governance) at the local level.

Thirdly, I want to conclude with a theoretically inflected observation. Like any process of institution building, CBC affects the strategic selectivity of existing institutional fields. In other words, CBC appears to have a number of side effects on the capacity of certain actors to pursue certain strategies. As mentioned above, it contributes to developing an organizational base for regional development agencies operating across borders, i.e. the Euroregional secretariats. There is some empirical evidence suggesting that these agencies might be of particular interest for actors keen on marketing a cross-border territory for attracting inward investment. But similar strategically selective adjustments also apply to the supra-local realm. In the emerging 'Europolity', new channels for shaping policy decisions have been opened up providing opportunity structures for new actor formation on a transnational level. In the case of CBC, the most visible expression of such transnational interaction is the Association of European Border Regions, operated from the secretariat of the EUREGIO. Together with other, more spontaneous, initiatives of collective action among border and cross-border regions, it can be expected that they will at least succeed in shaping their own policy field, i.e. INTERREG III, in the next programming period of the Structural Funds.

Acknowledgements -- I am particularly indebted to Bob Jessop as well as to Neil Brenner, Martin O'Brien and Majid Yar for their helpful remarks and criticisms on various versions as well as their linguistic advice. Finally, I thank two anonymous referees and the editors for their comments and suggestions, which decisively contributed to clarifying the argument. The usual disclaimer applies.

\section{REFERENCES}

ASSOCIATION OF EUROPEAN BORDER REGIONS (AEBR)(1997) Practical Guide to Cross-border Cooperation. AEBR, European Commission, Enschede.

AYKAC A. (1994) Transborder Regionalization. Libertas, Sindelfingen.

BECK J. (1997) Netzwerke in der transnationalen Regionalpolitik: Rahmenbedingungen, Funktionsweise, Folgen. Nomos, Baden-Baden.

CHURCH A. and REID P. (1996) Urban power, international networks and competition: the example of cross-border cooperation, Urban Studies 33( 8), 1, 297-318.

CHURCH A. and REID P. (1999) Cross-border co-operation, institutionalization and political space across the English Channel, Reg. Studies 33, 643-55.

COCHRANE A., PECK J. and TICKELL A. (1996) Manchester plays games: exploring the local politics of globalization, Urban Studies 33( 8), 1, 319-36.

DENTERS B., SCHOBBEN R. and VAN DER VEEN A. (1998) Governance of European border regions: a juridical, economic and political science approach with an application to the Dutch-German and the DutchBelgian border, in BRUNN G. and SCHMITT-EGNER P. (Eds) Grenzuberschreitende Zusammenarbeit in Europa. Nomos, Baden-Baden.

DOLEZ B. (1996) Le protocole additionnel a la convention-cadre europeenne sur la cooperation transfrontaliere des collectivites ou autorites territoriales, Revue Generale de Droit Internationale Public $100(4), 1,005-22$.

DUCHACEK I. D., LATOUCHE D. and STEVENSON G. (1988) Perforated Sovereignties and International Relations: Transsovereign Contacts of Subnational Governments. Greenwood Press, Westport, CT.

GOINGA K. (1995) Das alltagliche Leben in der Praxis. EUREGIO, Gronau. 
GRANOVETTER M. and SWEDBERG R. (Eds) (1992) The Sociology of Economic Lift. Westview Press, Boulder, CO.

HAUSNER J., JESSOP B. and NIELSEN K. (Eds) (1995) Strategic Choice and Path-dependency in Postsocialism: Institutional Dynamics in the Transformation Process. Edward Elgar, Cheltenham.

HEINELT H. and SMITH R. (Eds) (1996) Policy Networks and European Structural Funds. Avebury, Aldershot.

IMMERGUT E. M. (1998) The theoretical core of the New Institutionalism, Politics \& Society 26( 1 ), 5-4.

JESSOP B. (1996) Interpretive sociology and the dialectic of structure and agency, Theory, Culture \& Society 13( 1 ), 119-28.

JESSOP B. (1997) The governance of complexity and the complexity of governance: preliminary remarks on some problems and limits of economic guidance, in AMIN A. and HAUSNER J. (Eds) Beyond Market and Hierarchy: Interactive Governance and Social Complexity, pp. 95-128. Edward Elgar, Cheltenham.

LE GALES P. (1998) Regulation and governance of European cities, Int. J. Urban \& Reg. Res. 22( $\underline{3}$ ), 482506.

LIBERDA E. (1996) Regionalentwicklung in Grenzregionen: Eine Euregio als Regionalen twicklungsstrategie?. Passavia Universitatsverlag, Passau.

LUVERA B. (1996) Oltre il Confine: Regionalismo Europeo e Nuovi Nazionalismi in Trentino-Alto Adige. Il Mulino, Bologna.

MARCH J. G. and OLSEN J. P. (1989) Rediscovering Institutions: The Organizational Basis of Politics. Free Press, New York.

MARIN B. (Ed) (1990) Governance and Generalized Exchange: Self-organizing Policy Networks in Action. Campus/Westview, Frankfurt/Main, Boulder, CO.

MESSNER D. (1997) The Network Society. Cass, London.

MORATA F. (1996) Barcelone et la Catalogne dans l'arene europeenne, in BALME R. (Ed) Les Politiques du Neo-regionalisme, pp. 107-32. Economica, Paris.

MURPHY A. (1993) Emerging regional linkages within the European Community: challenging the dominance of the state, Tijdschr. Econ. Soc. Geogr. 84(2), 103-18.

PERKMANN M. (1998) Social integration and system integration: reconsidering the classical distinction, Sociology 32( $\underline{3})$, 491-507.

POWELL W. and DI MAGGIO P. (Eds) (1990) The New Institutionalism in Organizational Analysis. University of Chicago Press, Chicago.

RHODES R. A. W. (1990) Policy networks: a British perspective, J. Theoretical Politics 2, 293-317.

SCHACK M. (1997) Grenzuberschreitende Zusammenarbeit an der deutsch-niederlandischen Grenze. Institut for Graensegionsforskning, Aabenraa.

SCHAPPF F. W. (1991) Political institutions, decision styles, and policy choices, in CZADA R. and WINDHOFF-HERITIER A. (Eds) Political Choice: Institutions, Rules and the Limits of Rationality. Campus/Westview, Frankfurt (Main)/Boulder, CO.

\section{NOTES}

(n1.) The empirical evidence on the 'Pro Europa Viadrina' is based on interviews carried out in 1998 as well as policy documents. 
(n2.) For instance, it is used in the case of the Euroregion Tyrol (Austria/Italy) that does not involve any municipalities and has no common secretariat or council (LUVERA, 1996).

(n3.) For example, a stichting in the Netherlands or an eingetragener Verein in Germany. In the case of Dutch-German Euroregions, some EU regional associations on the German side are members in the Dutch stichting.

(n4.) Madrid Outline Convention on Transfrontier Cooperation between Territorial Communities or Authorities.

(n5.) Borders with non-EU Member States.

(n6.) The notion of 'concentration' refers to the degree to which centrally controlled administrative units are dispersed over the territory. Thus, in France, a concentrated agency would operate from Paris, while a deconcentrated unit would be located in the province while always being under the control of central government.

(n7.) For a synthetic overview, see IMMERGUT, 1998.

(n8.) For example, see the Inn-Salzach-Euregio on the Austrian-German border (LIBERDA, 1996), the Viadrina (Germany-Poland) or some of the CBC initiatives on the Dutch-German border (DENTERS et al., 1998).

(n9.) Brandenburg is the Eastern German Land surrounding Berlin and bordering to Poland.

(n10.) For instance, in the German part of the Viadrina, INTERREG subsidies amount to approximately 1$2 \%$ of public expenditures for economic policies and infrastructures. In the EUREGIO the yearly membership fee paid in by the German member municipalities is approximately 0-3 ECU per inhabitant (GOINGA, 1995, p. 40).

(n11.) The AEBR operates LACE-TAP (Linkage Assistance and Cooperation for the European Border Regions --Technical Assistance and Promotion), a measure funded by the European Commission to assist INTERREG implementation. 
Table 1. Types of interregional and cross-border co-operation with examples

\begin{tabular}{|l|l|l|}
\hline geographical scope & \multicolumn{1}{|c|}{ small } & \multicolumn{1}{c|}{ large } \\
\hline contiguous territories & $\begin{array}{l}\text { cross-border regions (CBRs) } \\
\text { ('EUREGIO') }\end{array}$ & $\begin{array}{l}\text { working communities } \\
\text { ('Arge Alp') }\end{array}$ \\
\hline non-contiguous territories & $\begin{array}{l}\text { inter-regional co-operation } \\
\text { ('Four Motors for Europe') }\end{array}$ & $\begin{array}{l}\text { peak associations } \\
\text { ('Association of European Border } \\
\text { Regions') }\end{array}$ \\
\hline
\end{tabular}


fig. 2: The implementation of INTERREG

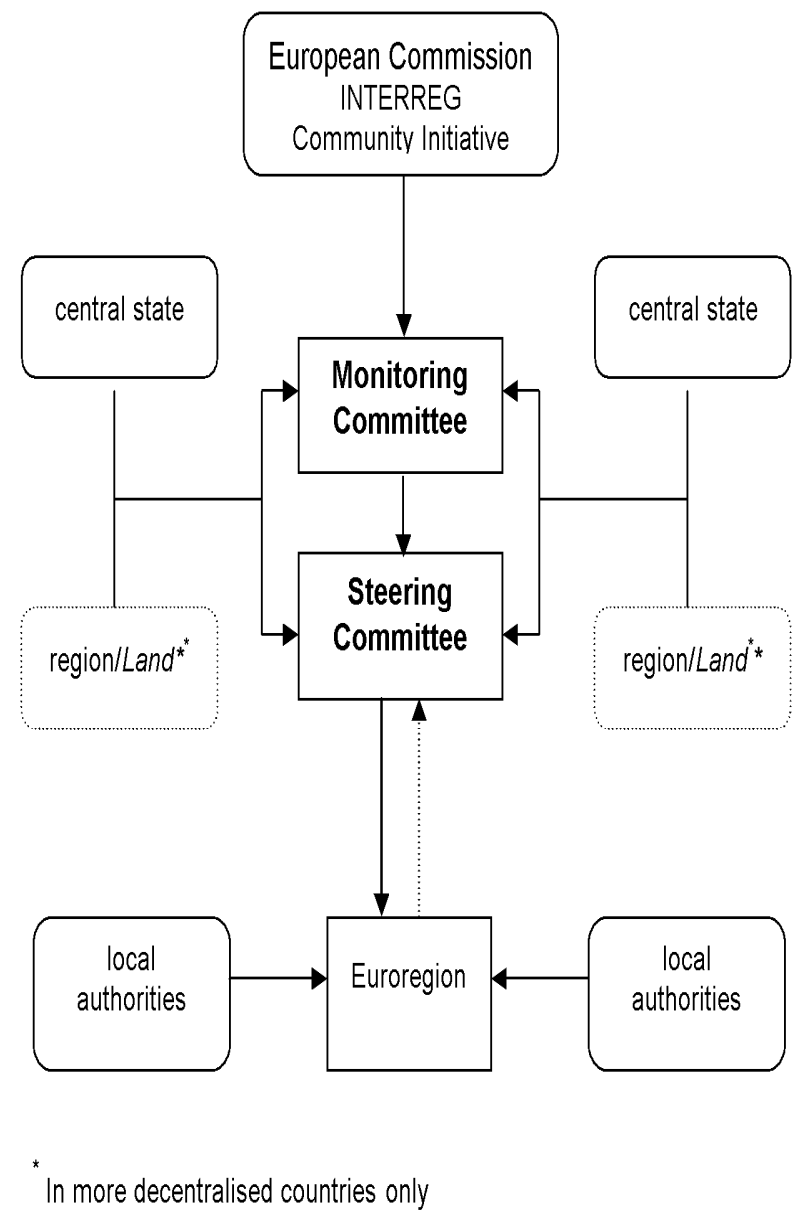

